\title{
COMBINATION TREATMENT WITH OXALIPLATIN AND MANGIFERIN CAUSES INCREASED APOPTOSIS AND DOWNREGULATION OF NFKB IN CANCER CELL LINES
}

\author{
D. du Plessis-Stoman ${ }^{a}$, J.G.H. du Preez ${ }^{b}$ and M. van de Venter ${ }^{a *}$ \\ ${ }^{\mathrm{a}}$ Department of Biochemistry and Microbiology, ${ }^{\mathrm{b}}$ Department of Chemistry, PO Box 77000, Nelson \\ Mandela Metropolitan University, Port Elizabeth, 6031, South Africa \\ * E-mail: Maryna.vandeventer@nmmu.ac.za
}

\begin{abstract}
Mangiferin-mediated down-regulation of NFKB showed potential for chemotherapeutic agent-mediated cell death, suggesting a role in combination therapy for cancer. In this study the combined mechanism of the anticancer action of oxaliplatin and mangiferin was investigated. MTT dose response curves, trypan blue staining, caspase 3 assays as well as DNA cell cycle analyses were performed on HeLa, HT29 and MCF7 cancer cell lines, with and without the addition of 10 $\mu \mathrm{g} / \mathrm{ml}$ mangiferin. Mitochondrial membrane potential, DNA fragmentation, resistance induction studies and NFkB assays were performed on HT29 cells only. Addition of $10 \mu \mathrm{g} / \mathrm{ml}$ mangiferin reduced oxaliplatin IC $_{50}$ values in HT29 (3.4 fold) and HeLa (1.7 fold) cells in the MTT assay while reducing trypan blue staining. This was accompanied by increased caspase 3 activation and DNA fragmentation and a delay in the S-phase of the cell cycle. Mitochondrial membrane permeabilization was not enhanced in the combination treatment. Mangiferin was shown to cause a reduction of NF- $\mathrm{kB}$ activation in HT29 cells rendered resistant to oxaliplatin. The present study indicates that mangiferin in combination with oxaliplatin favours apoptotic cell death and thereby improves the efficacy of oxaliplatin in vitro. In addition, combination therapy with mangiferin may also counteract the development of resistance in cancer cell lines.
\end{abstract}

Keywords: Oxaliplatin, Mangiferin, Combination treatment, Apoptosis, Drug resistance

\section{Introduction}

Cancer is an important public health concern around the world and the application of inorganic chemistry to medicine is a fast developing field (Parker et al., 1997; Walker and Walker, 1999). Novel therapeutic and diagnostic metal complexes are having a vast impact on medical practice. Advances in bio-coordination chemistry are crucial for improving the design of compounds to reduce toxic side effects and to aid in the understanding of their mechanisms of action (Sadler and Guo, 1998). At the same time traditional medicine is an integral part of South African cultural life, a position that is unlikely to change to any significant degree in years to come. It is estimated that between 12 and 15 million South Africans depend on traditional herbal medicines from as many as 700 indigenous plant species (Duncan et al., 1999).

The platinum drugs represent a unique and important class of anti-tumour agents. The discovery of cisplatin in the 1970s has revolutionized the chemotherapy of human cancer (Gonzalez et al., 2001). Unfortunately the full therapeutic potential of cisplatin has not been realized due to the serious side effects and the emergence of cisplatin-resistant tumour cells related to treatment with cisplatin (Walker and Walker, 1999). Many second-generation cisplatin-analogues have been synthesized and some of these, such as oxaliplatin, have been shown to produce the same therapeutic effects as cisplatin, but with lower required doses and reduced side-effects. Oxaliplatin is also clinically active in metastatic colorectal cancer, whereas cisplatin has a very low efficiency (Sergent et al., 2002).

The anticancer properties of tea are well known, and the tumour inhibition potential of certain polyphenolic compounds from green and black tea has been well documented (Marnewick et al., 2000; Marnewick et al., 2004; Marnewick et al., 2005). Honey-bush tea is a South African herbal beverage that is currently receiving prominent attention. Honey-bush tea is prepared from the leaves, stems and flowers of several Cyclopia spp. The major phenolic components of the unprocessed South African honey-bush tea are the xanthone, mangiferin and the flavanone, hesperidin (Marnewick et al., 2005).

Mangiferin is a natural polyphenol known to exhibit anti-inflammatory, antioxidant, and antiviral effects, though the molecular mechanism underlying these effects has not been well characterized. NF- $\mathrm{KB}$ plays an important role in these processes; hence it may be possible that mangiferin modulates NFkB activation.

$\mathrm{NF \kappa B}$ is a transcription factor that exerts anti-apoptotic effects and is often activated in cancer cells in response to chemotherapeutic agents. This promotes cancer therapy resistance in tumours (Baldwin, 2001). The improper activation of $\mathrm{NF \kappa B}$ in diseases such as tumourigenesis (Paul et al., 2006; Lee et al., 2008) has been linked to TNF $\alpha$ and other members of its superfamily. Through the activation of $\mathrm{NF} \kappa \mathrm{B}, \mathrm{TNF} \alpha$ induces the expression of various genes that can be involved in tissue invasion and metastasis. In addition, activation of $\mathrm{NF \kappa B}$ can suppress apoptosis, which is likely to enhance tumourigenesis and may also play a role in chemotherapeutic agent resistance. Sarkar et al. (2004) showed that mangiferin blocks tumour necrosis factor (TNF)-induced NFKB activation and NFKB-dependent genes like ICAM1 and COX2. The effect was mediated through inhibition of IKB (inhibitor proteins)-kinase complex (IKK) activation and subsequent blocking of phosphorylation and degradation of IKB- $\alpha$ (inhibitor protein $\alpha$ ). Mangiferin inhibits TNF-induced p65 phosphorylation as well as translocation to the nucleus and also inhibits $\mathrm{NF \kappa B}$ activation induced by other inflammatory agents. It has 
previously been shown that the development of anti-cancer drugs that can "switch" the function of NFKB from anti-apoptotic to pro-apoptotic may prove to be beneficial in the fight against cancer (Perkins, 2000; Perkins, 2004). Supranormal activation of $\mathrm{NF \kappa B}$ is connected to cancer. Active NFKB promotes tumour growth by increasing the transcription of genes that are: anti-apoptotic; inducers of cell proliferation; pro-angiogenic; pro-metastatic and responsible for other cellular mechanisms related to tumour growth. Hence, tumour prevention may be achieved through inhibition of abnormally active NFkB (Perkins, 2000; Perkins, 2004).

Mangiferin's ability to inhibit NFKB and increase the intracellular GSH levels, suggest that it may be a potent agent for anti-inflammatory and antioxidant therapy. Mangiferin-mediated down-regulation of NFkB also shows potential for chemotherapeutic agent-mediated cell death, suggesting a role in combination therapy for cancer (Sarkar et al., 2004). In this study the combined mechanism of the anticancer action of oxaliplatin and mangiferin was investigated to determine whether such combination treatment results in enhanced apoptosis induction, as well as to determine whether mangiferin may counteract the development of resistance to oxaliplatin by reducing active NFKB levels.

\section{Methods \\ Drugs}

Oxaliplatin solutions were prepared fresh on the day of use by dissolving the required concentration in RPMI1640 (Sigma) containing 10\% fetal calf serum (Delta Bioproducts, South Africa) by vortexing (1 min) followed by sonication (15 mins). Mangiferin was purchased from Sigma and the required concentrations prepared fresh in RPMI1640 containing $10 \%$ fetal calf serum on the day of use. The concentration of mangiferin used was $10 \mu \mathrm{g} / \mathrm{ml}$ (Sarkar et al., 2004).

\section{Cell Lines}

Three human cancer cell lines, HeLa (cervical cancer), HT29 (colon cancer) and MCF7 (breast cancer), were maintained in $10 \mathrm{~cm}$ culture dishes (Nunc) at $37^{\circ} \mathrm{C}$ in a humidified incubator containing $5 \% \mathrm{CO}_{2}$ in growth medium (RPMI1640 supplemented with $10 \%$ fetal calf serum).

\section{Dose response curves.}

Dose response curves were performed by using the MTT assay (Sigma) and the $\mathrm{IC}_{50}$ values were calculated using the GraphPad Prism4 software package. Cells $(200 \mu l$ per well) were seeded in flat-bottom 96 well culture plates (Nunc) at 30000 cells per milliliter and incubated overnight at $37^{\circ} \mathrm{C}$ in a humidified incubator containing $5 \% \mathrm{CO}_{2}$. Cells were allowed to attach and recover for $24 \mathrm{hrs}$ before oxaliplatin was added to the wells at concentrations of $100,50,25,10,5$ and $1 \mu \mathrm{M}$, with and without the addition of $10 \mu \mathrm{g} / \mathrm{ml}$ mangiferin, and incubated for $48 \mathrm{hrs}$ before the MTT assay was performed. A stock solution of MTT was prepared in PBSA $(5 \mathrm{mg} / \mathrm{ml})$ and further diluted to $0.5 \mathrm{mg} / \mathrm{ml}$ with growth medium. The medium from each well was replaced with $200 \mu \mathrm{L}$ MTT solution before the plates were incubated for another 3 hrs. MTT solution was replaced by $200 \mu \mathrm{L}$ DMSO and absorbance read at $540 \mathrm{~nm}$ on a Labsystems Multiskan MS Plate Reader.

\section{Caspase 3 activity}

Caspase 3 activity was determined using the Cleaved Caspase 3 (Asp 175) Alexa Fluor ${ }^{\circledR} 488$ Antibody (Beckman Coulter). Cells were seeded into $10 \mathrm{~cm}$ cell culture dishes (Nunc) at $1.15 \times 10^{5}$ cells per $\mathrm{ml}$ and incubated in a $37^{\circ} \mathrm{C}$ incubator supplemented with $5 \% \mathrm{CO}_{2}$ for 24 hours before $10 \mu \mathrm{M}$ of oxaliplatin was added, with and without the addition of $10 \mu \mathrm{g} / \mathrm{ml}$ mangiferin, and incubated for $15 \mathrm{hrs}$. The assay was performed, as per supplied instructions, and analyzed on a Beckman Coulter FC500 flow cytometer.

\section{Trypan blue assay}

The trypan blue assay was performed using a standard $0.4 \%$ trypan blue solution (Sigma) in phosphate buffered saline without calcium or magnesium. Cells ( $1 \mathrm{ml}$ per well) were seeded in flat-bottom 24 well culture plates (Nunc) at 500 000 cells per milliliter and incubated overnight at $37^{\circ} \mathrm{C}$ in a humidified incubator containing $5 \% \mathrm{CO}_{2}$. Cells were allowed to attach and recover for 24 hours before they were exposed to $10 \mu \mathrm{M}$ of oxaliplatin, with and without the addition of $10 \mu \mathrm{g} / \mathrm{ml}$ mangiferin. The cells were trypsinised and counted with a heamocytometer in a 1:1 dilution of cells in a $0.4 \%$ trypan blue solution and the percentage of non-viable cells was calculated.

\section{DNA cell cycle analysis}

DNA cell cycle analysis was performed using the Coulter ${ }^{\circledR}$ DNA Prep ${ }^{\mathrm{TM}}$ Reagents Kit (Beckman Coulter). Cells were seeded and treated as described for the caspase 3 assay. The assay was performed as per kit instructions and the results analyzed on a Beckman Coulter FC500 flow cytometer. 
Du Plessis-Stoman et al., Afr J Tradit Complement Altern Med. (2011) 8(2):177-184 179

\section{DNA fragmentation assay}

DNA fragmentation assays were performed using the Apo-BRDU ${ }^{\mathrm{tm}}$ kit (Phoenix Flow Systems). HT29 cells (5 mL aliquots) were seeded into $50 \mathrm{ml}$ non-adherent cell culture flasks (Nunc) at a density of $100000 \mathrm{cells} / \mathrm{mL}$ and were incubated for $48 \mathrm{hrs}$ with $10 \mu \mathrm{M}$ of oxaliplatin, with and without the addition of $10 \mu \mathrm{g} / \mathrm{ml}$ mangiferin, before the assay was performed as per kit instructions and the results analyzed on a Beckman Coulter FC500 flow cytometer.

\section{Mitochondrial transmembrane potential assay}

Mitochondrial transmembrane potential studies were performed using the Guava ${ }^{\circledR}$ EasyCyte $^{\mathrm{TM}}$ MitoPotential ${ }^{\mathrm{TM}} \mathrm{Kit}$ (Guava Technologies). HT29 cells were seeded and treated as for DNA fragmentation, before the assay was performed as per kit instructions and the results analyzed on a Beckman Coulter FC500 flow cytometer.

\section{Induction of resistance}

HT29 colon cancer cells were exposed intermittently and incrementally to oxaliplatin, with and without the addition of $10 \mu \mathrm{g} / \mathrm{ml}$ mangiferin. Table 1 illustrates the conditions for inducing resistance in these cells. The degree of resistance was determined by performing dose response curves on these cells as above.

Table 1. The conditions for inducing resistance to oxaliplatin in cancer cell lines.

\begin{tabular}{cc}
\hline [Platinum drug] $(\boldsymbol{\mu M})$ & Time exposed (hours) \\
\hline 10 & 0.5 \\
10 & 1.0 \\
10 & 1.5 \\
100 & 0.5 \\
100 & 1.0 \\
100 & 1.5 \\
100 & 1.0 \\
100 & 1.0 \\
\hline
\end{tabular}

\section{NF-кB Assay}

The Phospho-NF-кB p65 (Ser536) (93H1) Rabbit mAb (Alexa Fluor ${ }^{\circledR} 488$ Conjugate) Kit (Cell Signalling Technology) was used to study the effect of resistance, with and without the addition of $10 \mu \mathrm{g} / \mathrm{ml}$ mangiferin, on the expression of NF- $\mathrm{\kappa B}$. HT29 cells ( $5 \mathrm{~mL}$ aliquots) were seeded into $50 \mathrm{ml}$ non-adherent cell culture flasks (Nunc) at a density of 100000 cells/ $\mathrm{mL}$ and were incubated for $48 \mathrm{hrs}$ with $10 \mu \mathrm{M}$ of oxaliplatin, with and without the addition of $10 \mu \mathrm{g} / \mathrm{ml}$ mangiferin, before the assay was performed as per kit instructions and the results analyzed on a Beckman Coulter FC500 flow cytometer with a minimum of 10000 events being recorded.

\section{Statistical analysis}

Statistical analysis was performed via the Student's T-test. Certain experiments (trypan blue assay and caspase 3 assay) were performed in duplicate and therefore the average deviation of the values is depicted on the graphs. For flow cytometric analysis a minimum of 10000 events were recorded.

\section{Results and Discussion}

The results obtained in Table 2 indicate that mangiferin enhances the effect of oxaliplatin on HeLa and HT29 cells, as lower $\mathrm{IC}_{50}$ values were obtained in combination with mangiferin in these two cell lines. This was, however, not the case in MCF7 cells.

Table 2: $\mathrm{IC}_{50}$ values for oxaliplatin with and without the addition of $10 \mu \mathrm{g} / \mathrm{ml}$ mangiferin.

\begin{tabular}{llll}
\hline & \multicolumn{3}{c}{ IC50 $(\boldsymbol{\mu M})$} \\
\cline { 2 - 4 } Treatment & HeLa & HT29 & MCF7 \\
\hline Oxaliplatin & 11.92 & 12.30 & 6.21 \\
$\begin{array}{l}\text { Oxaliplatin + } \\
\text { manigferin }\end{array}$ & $6.86(1.7)$ & $3.63(3.4)$ & 8.31 \\
& & & $(0.75)$ \\
\hline
\end{tabular}

Brackets: Fold decrease in IC50 value compared to corresponding IC50 in absence of mangiferin. 
In contrast to the lower $\mathrm{IC}_{50}$ values in the presence of mangiferin, the trypan blue assay (Table 3) showed a decrease in the percentage of non-viable cells when treated with oxaliplatin plus mangiferin. A possible explanation for this discrepancy was that mangiferin favoured cell death as a result of apoptosis, rather than necrosis.

Table 3: Percentage of non-viable cells (according to the trypan blue assay) with and without the addition of $10 \mu \mathrm{g} / \mathrm{ml}$ mangiferin.

\begin{tabular}{llll}
\hline & \multicolumn{2}{l}{ \% Trypan positive cells } & \\
\cline { 2 - 4 } & HeLa & HT29 & MCF7 \\
\hline $\mathbf{1 0} \mu$ M Oxaliplatin & $80.74 \pm 1.13$ & $55.64 \pm 8.27$ & $54.17 \pm 4.17$ \\
$\mathbf{1 0} \boldsymbol{\mu M}$ Oxaliplatin + manigferin & $45.69 \pm 2.59$ & $42.58 \pm 3.38$ & $33.54 \pm 5.73$ \\
\hline
\end{tabular}

Values represent mean \pm average deviation, $n=2$

An increase in the percentage of activated caspase 3 (Figure 1), indicates that mangiferin indeed increased caspase 3 activation in combination with oxaliplatin. The MCF7 cell line does not express caspase 3 (Yang et al., 2001), therefore only HeLa and HT29 cell lines were tested for caspase 3 activities.

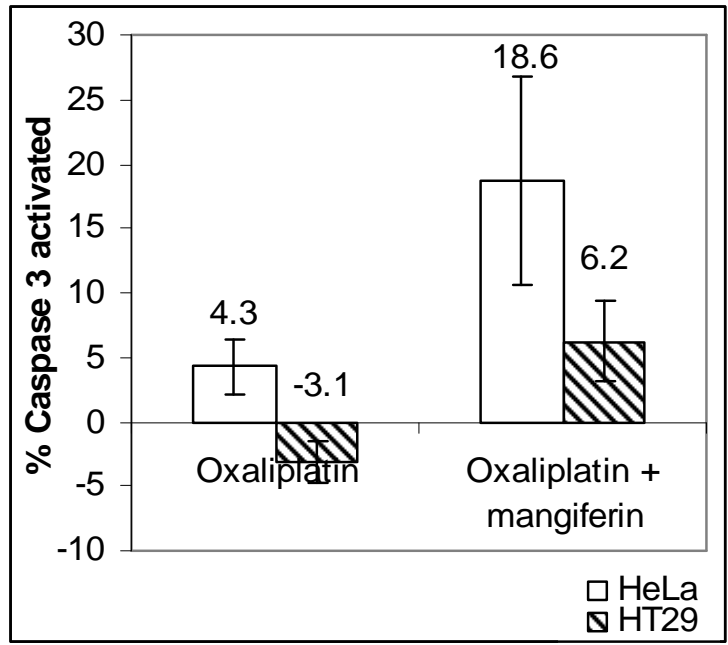

Figure 1: Percentage increase in activated caspase 3 with and without addition of $10 \mu \mathrm{g} / \mathrm{ml}$ mangiferin, relative to untreated control cells (values represent mean \pm average deviation, $n=2$ ).

The results obtained from the DNA cell cycle analysis of HT29 cells (Table 4) indicates that mangiferin causes a delay in the S-phase in combination with oxaliplatin whereas it had no effect on its own apart from an increase in the subG1 population from 2.6 to $6.2 \%$. The percentage apoptosis (cells in the sub-G1 peak) was further increased to $8.4 \%$ in the oxaliplatin/mangiferin combination treatment. This was also higher than the $6.4 \%$ observed in subG1 in the oxaliplatin only treatment. Similar results were obtained with MCF7 and HeLa cells (results not shown) and further experiments were performed on HT29 cells only. The DNA fragmentation assay (Figure 2) indicates that there was more DNA fragmentation in samples treated with oxaliplatin plus mangiferin than with oxaliplatin alone. From Figure 3 it is evident that both mangiferin and oxaliplatin decreased mitochondrial transmembrane potential with mangiferin having a greater effect. When added in combination, the ratio was not significantly different to that seen with oxaliplatin alone.

Table 4: The percentage of cells in the different DNA cell cycle phases.

\begin{tabular}{lllll}
\hline Complex & \multicolumn{4}{c}{ \% of Cells in different cell cycle phases } \\
\hline & SubG1 & G0/G1 & S & G2/M \\
\cline { 2 - 5 } Control & 2.6 & 43.7 & 27 & 23.4 \\
Control + mangiferin & 6.2 & 44.6 & 26.4 & 22.1 \\
Oxaliplatin & 6.4 & 40.2 & 24.8 & 26.4 \\
Oxaliplatin + mangiferin & 8.4 & 41 & 32.8 & 17.4 \\
\hline
\end{tabular}


Du Plessis-Stoman et al., Afr J Tradit Complement Altern Med. (2011) 8(2):177-184 181

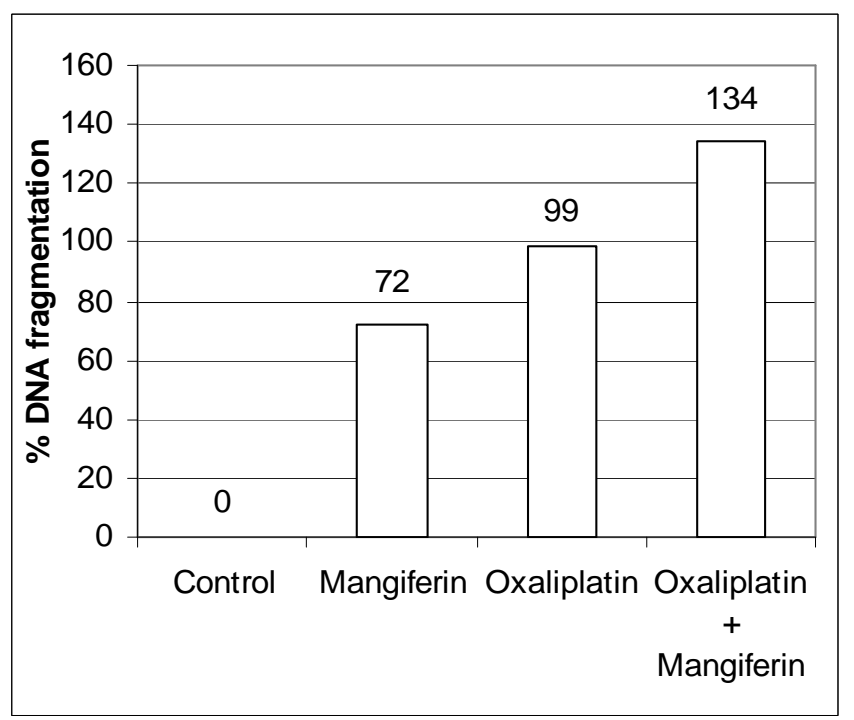

Figure 2: Percentage increase in DNA fragmentation in HT29 cells with and without the addition of $10 \mu \mathrm{g} / \mathrm{ml}$ mangiferin, relative to untreated control cells (bars indicate values from single experiment; a repeat of this experiment showed similar trends).

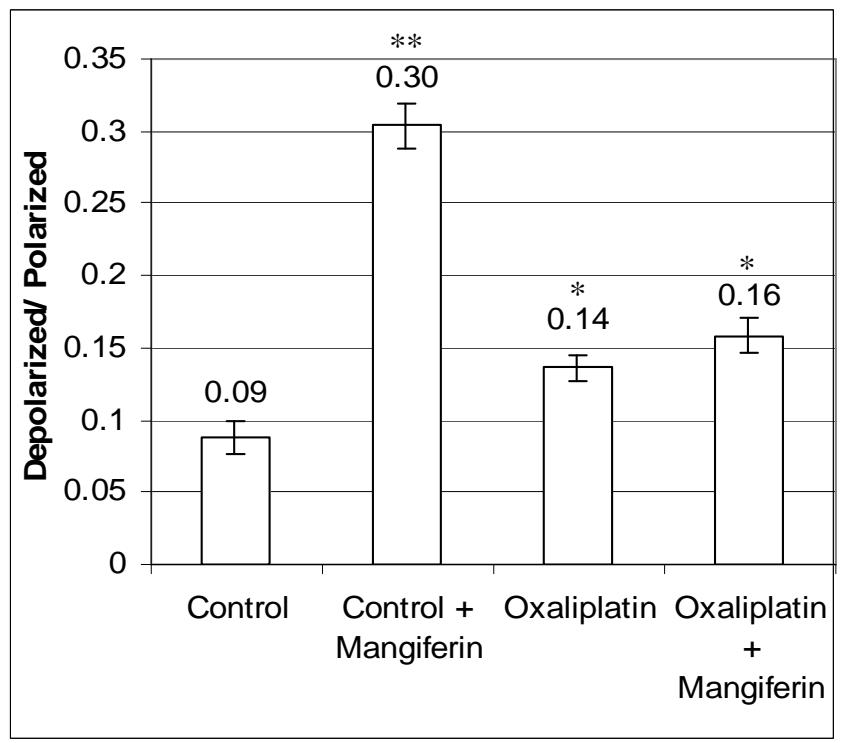

Figure 3: Mitochondrial membrane potential, expressed as the ratio of depolarized to polarized membranes in HT29 cells with and without the addition of $10 \mu \mathrm{g} / \mathrm{ml}$ mangiferin (values represent mean \pm standard deviation; $\mathrm{n}=3$ ). (** $\mathrm{p} \leq$ $0.001, * \mathrm{p} \leq 0.05$ compared to control; no significant difference between Oxaliplatin and Oxaliplatin + mangiferin).

The $\mathrm{IC}_{50}$ concentrations depicted in Table 5 indicates that oxaliplatin resistant HT29 and HeLa cells had higher $\mathrm{IC}_{50}$ values than non-resistant cells and that the presence of $10 \mu \mathrm{g} / \mathrm{ml}$ mangiferin lowered the $\mathrm{IC}_{50}$ concentration in both nonresistant and resistant cells. MCF7 cells did not appear to develop resistance to oxaliplatin and mangiferin did not have the same sensitizing effect on this cell line as seen for HT29 and HeLa.

Table 5: The $\mathrm{IC}_{50}$ concentrations $(\mu \mathrm{M})$ of the platinum drugs for non-resistant (normal) as well as oxaliplatin resistant cancer cell lines, with and without the addition of $10 \mu \mathrm{g} / \mathrm{ml}$ mangiferin.

\begin{tabular}{lllllll}
\hline Compound & $\begin{array}{l}\text { Normal } \\
\text { HeLa }\end{array}$ & $\begin{array}{l}\text { Resistant } \\
\text { HeLa }\end{array}$ & $\begin{array}{l}\text { Normal } \\
\text { HT29 }\end{array}$ & $\begin{array}{l}\text { Resistant } \\
\text { HT29 }\end{array}$ & $\begin{array}{l}\text { Normal } \\
\text { MCF7 }\end{array}$ & $\begin{array}{l}\text { Resistant } \\
\text { MCF7 }\end{array}$ \\
\hline Oxaliplatin & 3 & 12 & 6 & 12 & 8 & 6 \\
$\begin{array}{l}\text { Oxaliplatin } \\
\text { and }\end{array}$ & 4 & 7 & 3 & 4 & 5 & 8 \\
Mangiferin & & & & & & \\
\hline
\end{tabular}


The NFkB assay (Figure 4) indicates that oxaliplatin resistant HT29 cells had a higher amount of activated NFkB than normal HT29 cells. This amount of activated NFKB was reduced to below that of normal control cells when resistance was induced in the presence of mangiferin. Therefore, mangiferin has been shown to reduce the amount of activated NFKB associated with resistant tumour cells and may prove beneficial in the prevention of resistance to platinum anticancer drugs in tumour cells.

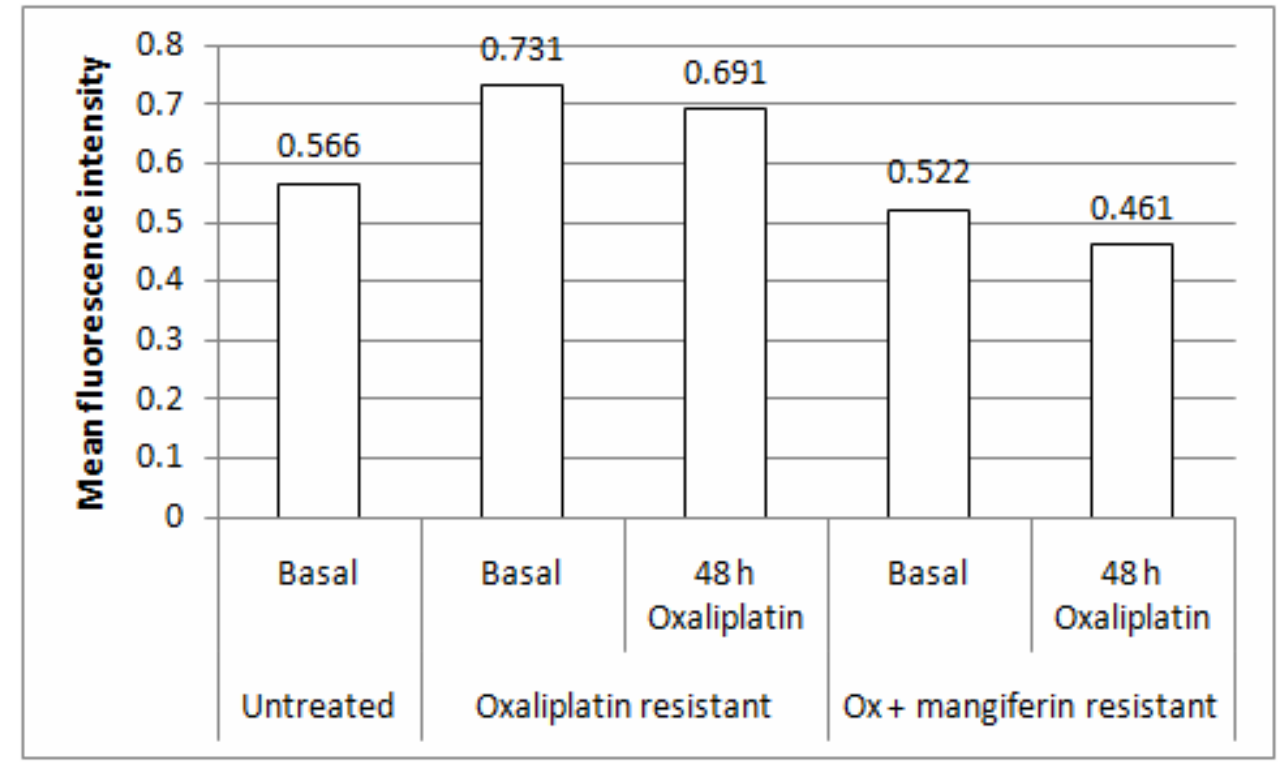

Figure 4: The amount of activated NF- $\mathrm{KB}$ (expressed as mean fluorescence intensity) in untreated and resistance-induced HT29 cells. Oxaliplatin resistance was induced as described under Materials and Methods, through intermittent, incremental exposure to Oxaliplatin (oxaliplatin resistant) or Oxaliplatin $+10 \mu \mathrm{g} / \mathrm{ml}$ mangiferin (ox + mangiferin resistant). These cells were finally seeded into culture flasks and levels of activated NF- $\mathrm{BB}$ measured in cells that received no further treatment (basal) or $10 \mu \mathrm{M}$ Oxaliplatin for a further $48 \mathrm{hrs}$.

Normal cells treated with mangiferin alone showed an increased amount of NFKB activation, whereas treatment of normal cells with Oxaliplatin alone or in combination with mangiferin showed a similar, reduced, amount of activation. This suggests that mangiferin in combination with platinum containing complexes might have a synergistic effect and does not act as an NFאB inhibitor/ anticancer agent on its own. Although treatment of normal cells with mangiferin in combination with Oxaliplatin does not decrease the amount of activated NFKB more than when these cells are treated with Oxaliplatin alone, the 3.4 fold decrease in the $\mathrm{IC}_{50}$ concentration (Table 2) does indicate an enhanced anticancer action of this combination compared to Oxaliplatin alone. Figure 5 shows that after an additional treatment of the Oxaliplatin resistant control cells there is a slight decrease in the amount of NFKB activated, but this amount is decreased to a value even lower than that of normal control cells when Oxaliplatin and mangiferin resistant control cells are treated with Oxaliplatin. These results indicate that mangiferin in combination with Oxaliplatin acts as an NFKB inhibitor. It has been shown previously that the development of anti-cancer drugs that can "switch" the function of NFKB from anti-apoptotic to pro-apoptotic may prove to be beneficial in the fight against cancer and that tumour prevention may be achieved through inhibition of abnormally active NFkB (Perkins, 2000; Perkins, 2004).

Cisplatin showed great promise in the treatment of cancer, however, due to the numerous toxic side effects and the emergence of cisplatin resistant cell lines, drugs with less toxic side effects, improved cytotoxicity against cancer cells and activity against cisplatin resistant cell lines are urgently needed. Sarkar et al. (Sarkar et al., 2004) showed that mangiferin enhanced cell death caused by various apoptotic agents, including cisplatin. Mangiferin is a natural polyphenol found in Cyclopia spp., Canscora decussata (Bhattacharya et al., 1972) and Mangifera indica (Muruganandan et al., 2005). Although some controversy still exists, Honeybush tea (Cyclopia spp.), which is a rich source of antioxidants, is sometimes used in conjunction with chemotherapy to reduce the side-effects (Drisko et al., 2003a, b; Lawenda et al., 2008). This study was therefore done to determine whether mangiferin could enhance the in vitro anticancer activity of oxaliplatin.

The decreased $\mathrm{IC}_{50}$ values for oxaliplatin when combined with $10 \mu \mathrm{g} / \mathrm{ml}$ mangiferin (Table 2) were very promising. Furthermore, the fact that the highest fold decrease occurred in the HT29 cells treated with oxaliplatin in combination with mangiferin is very significant, since oxaliplatin is clinically used to treat colon cancer (Martin et al., 2000). A decrease in the percentage of non-viable cells was observed in the trypan blue assay (Table 3). Trypan blue stains dead/ necrotic cells with "leaky" cell membranes, hence a decrease in the percentage of non-viable cells from this assay indicates less necrosis has taken place. These results therefore show strong evidence that mangiferin favours apoptotic cell death instead of necrosis. 
Caspases (cysteine aspartic acid-specific proteases) play key roles in apoptosis of mammalian cells. The fact that an increase in the caspase 3 activity (Figure 1) was observed during combination treatment with oxaliplatin and mangiferin in both HeLa and HT29 cells indicates that the decreased $\mathrm{IC}_{50}$ values may be due to increased apoptosis.

The results obtained from the DNA cell cycle analysis (Table 4) shows a slight increase in G2/M-phase in oxaliplatin treated cells. Fujie et al. (Fujie et al., 2005) also showed that oxaliplatin causes an S or G2M phase delay in the cell cycle of HT29 cells. Although mangiferin alone did not induce cell cycle arrest, the presence of mangiferin in combination with oxaliplatin shows a delay in the S-phase. The percentage of apoptotic cells were also increased in the cells subjected to a combination treatment. The Sub-G1 phase refers evidence for apoptosis. Apoptotic cells can be seen to the left of the G0/G1 peak due to DNA fragmentation occurring during apoptosis, DNA is lost from the permeabilized cells thus rendering these cells with less DNA (Kwon et al., 2005). This increased apoptosis was verified by a DNA fragmentation assay (Figure 2) that showed an increase in the amount of DNA fragmentation in HT29 cells subjected to a combination treatment in contrast to cells treated with oxaliplatin alone.

The health and bioenergetic function of the mitochondria depend on its membrane potential $\left(\Delta \Psi_{m}\right)$. The preservation of $\Delta \Psi_{m}$ is essential during normal conditions and, especially, during conditions of stress and disease. Depolarization of the membrane results in a reduction of ATP production and is also thought to precipitate the release of pro-apoptotic factors in some cell systems; hence there are good reasons to search for therapeutic agents to decrease $\Delta \Psi_{m}$ as possible pro-apoptotic drugs, for example, in the case of cancer (Wong and Cortopassi, 2002). Both mangiferin and oxaliplatin treatment caused a significant reduction in mitochondrial membrane potential (Figure 3). Therefore the apoptosis observed in the subG1 peak of the cell cycle analysis (Table 4) and the increase in DNA fragmentation was induced through a mitochondrial pathway. In combination, there was no significant increase in mitochondrial depolarization above that of oxaliplatin alone.

$\mathrm{NFKB}$ is a transcription factor that exerts anti-apoptotic effects and is often activated in cancer cells in response to chemotherapeutic agents. This promotes cancer therapy resistance in tumours (Baldwin, 2001). The improper activation of $\mathrm{NF} \kappa \mathrm{B}$ in diseases such as tumorigenesis (Paul et al., 2006; Lee et al., 2008) has been linked to TNF $\alpha$ and other members of its superfamily. Through the activation of $\mathrm{NF} \kappa \mathrm{B}, \mathrm{TNF} \alpha$ induces the expression of various genes that can be involved in tissue invasion and metastasis. In addition, activation of $\mathrm{NF \kappa B}$ can suppress apoptosis, which is likely to enhance tumorigenesis. Many natural compounds, including the phenolics, have been found to inhibit upstream signaling molecules that are involved in TNF $\alpha$ expression (Paul et al., 2006). Leiro et al. 2004 (Leiro et al., 2004) illustrated that mangiferin modulates the expression of a large number of genes that are critical for the regulation of apoptosis and tumorigenesis, and raised the possibility that it may be of value in the treatment of cancer.

Mabuchi et al. (Mabuchi et al., 2004) showed that combination therapy of cisplatin with an NFkB inhibitor would increase the therapeutic efficacy of cisplatin. Our results indicate that mangiferin is an NFKB inhibitor and that it increases the therapeutic efficacy of oxaliplatin (Table 2). Furthermore, we have shown evidence that mangiferin may counteract the development of resistance to oxaliplatin in HT29 colon cancer cells by reducing active NFkB levels (Figures 4 and 5).

\section{Conclusion}

The results obtained in this study indicate that mangiferin might be used as a combination therapy with platinum anticancer drugs in order to increase the efficacy of these drugs as well as counteract the development of drug-resistant cells. Unfortunately no published literature could be found to indicate how much mangiferin is present in a cup of tea such as Honeybush, nor how much mangiferin is absorbed through the gastro-intestinal tract. Such information would assist in extrapolating our in vitro results to the in vivo situation. Recent findings also point to a link between Stat 3 and NFkB activation and signaling pathways (Nadiminty et al., 2006; Lee et al., 2008) and it has been illustrated that a more effective strategy might be the simultaneous inhibition of both Stat 3 and $\mathrm{NF \kappa B}$, rather than individually. Therefore we suggest that the effect of mangiferin on Stat 3 activation should also be investigated in future.

\section{Acknowledgements}

The authors would like to thank Shimoda Biotech Pty (Ltd) for their continual support provided during this study.

\section{References}

1. Baldwin, A.S. (2001). Control of oncogenesis and cancer therapy resistance by the transcription factor NF-kappaB. Journal of Clinical Investigation, 107, 241-246.

2. Bhattacharya, S.K, Sanyal, A.K and Ghosal, S. (1972). Monoamine oxidase-inhibiting activity of mangiferin isolated from Canscora decussate. Naturwissenschaften, 59, 651.

3. Drisko, J.A, Chapman, J. and Hunter, V.J. (2003a). The use of antioxidants with first-line chemotherapy in two cases of ovarian cancer. Journal of the American College of Nutrition, 22: 118-123.

4. Drisko, J.A., Chapman, J. and Hunter, V.J. (2003b). The use of antioxidant therapies during chemotherapy. Gynecol. Oncol., 88, 434-439.

5. Duncan, A.C., Jager, A.K. and van Staden, J. (1999). Screening of Zulu medicinal plants for angiotensin converting enzyme (ACE) inhibitors. Journal of Ethnopharmacology, 68, 63-70. 
6. Fujie, Y., Yamamoto, H., Ngan, C.Y., Takagi, A., Hayashi, T., Suzuki, R., Ezumi, K., Takemasa, I., Ikeda, M., Sekimoto, M., Matsuura, N. and Monden, M. (2005). Oxaliplatin, a Potent Inhibitor of Survivin, Enhances Paclitaxel-induced Apoptosis and Mitotic Catastrophe in Colon Cancer Cells. Japanese Journal of Clinical Oncology, 35, 453-463.

7. Gonzalez, V.M., Fuertes, M.A., Alonso, C. and Perez, J.M. (2001). Is Cisplatin-Induced Cell Death Always Produced by Apoptosis. Molecular Pharmacology, 59, 657-663.

8. Kwon, H.J., Hong, Y.K., Kim, K.H., Han, C.H., Cho, S.H., Choi, J.S. and Byung-Woo, K. (2005). Methanolic extracts of Pterocarpus santalinus induces apoptisis in HeLa cells. Journal of Ethnopharmacology, 105, 229-234.

9. Lawenda, B.D., Kelly, K.M., Ladas, E.J., Sagar, S.M., Vickers, A. and Blumberg, J.B. (2008). Should supplemental antioxidant administration be avoided during chemotherapy and radiation therapy? Journal of the national cancer institute, 100, 773-783.

10. Lee, T.L., Yeh, J., Friedman, J., Yan, B., Yang, X., Yeh, N.T., van Waes, C. and Chen, Z. (2008). A signal network involving coactivated NF-kappaB and STAT3 and altered p53 modulates BAX/BCL-XL expression and promotes cell survival of head and neck squamous cell carcinomas. International Journal of Cancer, 122, 19871998.

11. Leiro, J., Arranza, J.A., Yanez, M., Ubeira, F.M., Sanmartın, M.L. and Orallo, F. (2004). Expression profiles of genes involved in the mouse nuclear factor-kappa B signal transduction pathway are modulated by mangiferin. International Immunopharmacology, 4, 763-778.

12. Mabuchi, S., Ohmichi, M., Nishio, Y., Hayasaka, T., Kimura, A., Ohta, T., Saito, M., Kawagoe, J., Takahashi, K., Yada-Hashimoto, N., Sakata, M., Motoyama, T., Kurachi, H., Tasaka, K. and Murata, Y. (2004). Inhibition of NFkB increases the efficacy of Cisplatin in in vitro and in vivo ovarian cancer models. The Journal of Biological Chemistry, 10, 1-39.

13. Marnewick, J., Gelderblom, W.C.A. and Joubert, E. (2000). An investigation on the antimutagenic properties of South African herbal teas. Mutation Research, 471, 157-166.

14. Marnewick, J.L., Batenburg, W., Swart, P., Joubert, E., Swanevelder, S., Swart, P. and Gelderblom, W.C.A. (2004). Ex vivo modulation of chemical-induced mutagenesis by subcellular liver fractions of rats treated with rooibos (Aspalathus linearis) tea, honeybush (Cyclopia intermedia) tea, as well as green and black (Camellia sinensis) teas. Mutation Research, 558, 145-154.

15. Marnewick, J., Joubert, E., Josepha, S., Swanevelder, S., Swart, P. and Gelderblom, W. (2005). Inhibition of tumour promotion in mouse skin by extracts of rooibos (Aspalathus linearis) and honeybush (Cyclopia intermedia), unique South African herbal teas. Cancer Letters, 224, 193-202.

16. Martin, A.G., Lockwood, G.F., Greenslade, D., Brienza, S., Bayssas, M. and Gamelin, E. (2000). Clinical Pharmacokinetics of Oxaliplatin: A Critical Review. Clinical Cancer Research, 6, 1205-1218.

17. Muruganandan, S., Srinivasan, K., Gupta, S., Gupta, P.K. and Lal, J. (2005). Effect of mangiferin on hyperglycemia and atherogenicity in streptozotocin diabetic rats. Journal of Ethnopharmacology, 97, 497-501.

18. Nadiminty, N., Lou, W., Lee, S.O., Lin, X., Trump, D.L. and Gao, A.C. (2006). Stat3 activation of NF-kB p100 processing involves CBP/ p300-mediated acetylation. PNAS, 103, 7264-7269.

19. Parker, S.H., Tong, T., Bolden, S. and Wingo, P.A. (1997). Cancer Statistics, 1997. CA Cancer J Clin, 47, 5-27.

20. Paul, A.T., Gohil, V.M. and Bhutani, K.K. (2006). Modulating TNF- $\alpha$ signaling with natural products. Drug Discovery Today, 11, 725-732.

21. Perkins, N. D. (2000). The Rel/NF-kB family: friend and foe. TIBS 25: 434-440.

22. Perkins, N. D. (2004). NF-kB: tumor promoter or suppressor? TRENDS in Cell Biology 14: 64-69.

23. Sadler, P.J. and Guo, Z. (1998). Metal complexes in medicine: Design and mechanism of action. Pure and Applied Chemistry, 70, 863-971.

24. Sarkar, A., Sreenivasan, Y., Ramesh, G.T. and Manna, S.K. (2004). $\beta$-D-Glucoside Suppresses Tumor Necrosis Factor-induced Activation of Nuclear Transcription Factor $\kappa \mathrm{B}$ but Potentiates Apoptosis. Journal of Biological Chemistry, 279, 33768-33781.

25. Sergent, C., Franco, N., Chapusot, C., Lizard-Nacol, S., Isambert, N., Correia, M. and Chauffert, B. (2002). Human colon cancer cells surviving high doses of cisplatin or oxaliplatin in vitro are not defective in DNA mismatch repair proteins. Cancer Chemotherapy Pharmacology, 49, 445-452.

26. Walker, E.M. and Walker, S.M. (1999). Evolution of chemotherapy with platinum compounds. Annals of Clinical and Laboratory Science, 29, 263-274.

27. Wong, A. and Cortopassi, J.A. (2002). High-throughput measurement of mitochondrial membrane potential in a neural cell line using a fluorescence plate reader. Biochemical and Biophysical Research Communications, 298, 750-754.

28. Yang, X., Sladek, T.L., Liu, X., Butler, B.R., Froelich, C.J. and Thor, A.D. (2001). Reconstitution of Caspase 3 Sensitizes MCF-7 Breast Cancer Cells to Doxorubicin- and Etoposide-induced Apoptosis. Cancer Research, 61, 348-354. 